\title{
Physical and Phytochemical Analysis of Justicia gendarussa Burm. F. Leaf Extracts
}

\author{
Aljon Victor G. Nibalvos ${ }^{1, *}$, Cristina H. Tan-Nibalvos ${ }^{2}$ and Jenny Rose U. Kruse ${ }^{1}$ \\ ${ }^{1}$ Faculty, College of Arts and Sciences, Eastern Samar State University, Borongan City, Eastern Samar, \\ Philippines; aljonvictorgalitnibalvos@gmail.com, nibalvosctan@gmail.com \\ ${ }^{2}$ Laboratory Technician, Natural Sciences Department, College of Arts and Sciences, Eastern Samar \\ State University, Borongan City, Eastern Samar, Philippines; jhenjerr77@yahoo.com.ph
}

\begin{abstract}
Objectives:

Methods: An experimental research design was used in this study based on phytochemicals screening, which includes the detection of major secondary metabolites. A qualitative analysis was done on the phytochemicals aspect, while qualitative and quantitative analyses were used to determine the physical properties of the plant extract. J. gendarussa leaf extract was subjected to physical examination to determine its (a) boiling point, (b) colour, (c) density, (d) odour, (e) pH and (f) miscibility. Phytochemical analysis of the extract was carried out to determine the presence of the following compounds: (a) alkaloid, (b) anthraquinone, (c) leucoanthocyanin, (d) phenolic compounds, (e) saponin, (f) steroid, (g) tannins and (h) terpenoids. Percent yield was also computed on the leaf extracts of J. gendarussa. Results: From the observed physical properties, it was generalised that the J. gendarussa leaf extract has a $103.3^{\circ} \mathrm{C}$ boiling point, a brown colour and pleasant odour, $1.02 \mathrm{~g} / \mathrm{mL}$ of density, a neutral $\mathrm{pH}$ of 7 and is a polar substance. By weighing the collected extracts of J. gendarussa and dividing it by its weight of its leaves, the percent yield was recorded to be at $30 \%$. It was documented by collecting about $30 \mathrm{~g}$ of crude J. gendarussa extract from the total $100 \mathrm{~g}$ of leaves used in the conduct of this study. Phytochemical analysis showed that only alkaloid and saponin are present in the plant extract of J. gendarussa leaves, and other secondary metabolites such as terpenoids, tannin, anthraquinone, leucoanthocyanin, phenolics and steroids were found to be absent in the plant extract. Improvements/further study: It is suggested that a further study should be conducted to characterise and quantify alkaloid and saponin in the extract of $J$. gendarussa. Also, a study using various methods of extraction and solvents is important to determine if there is a difference in secondary metabolite screening as well as to make use of $J$. gendarussa as a natural source of alkaloid and saponin.
\end{abstract}

Keywords: J. gendarussa, Chemical Analysis, Phytochemistry, Plant-derived Substances

\section{Introduction}

Most of the plants growing in our surroundings are ignored especially those that are wild. In the Philippines, some of these unnoticed plants, including Justicia gendarussa Burm. F., can be used to cure or prevent certain diseases.

Justicia gendarussa Burm. F. is a native plant to China, Sri Lanka, Malaysia, India and the Philippines. It is found at low to medium altitudes and is rarely cultivated. Justicia gendarussa Burm. F. is shade-loving, quick-growing, erect, branched evergreen shrub measuring 0.6-1.2 m in height. The leaves are simple, opposite, lanceolate or linear-lanceolate, acute at base, tapering into rounded apex, and glabrous shining $(8-12.5 \mathrm{~cm}$ long, $1.2-2 \mathrm{~cm}$ broad) with prominent purple veins beneath. The stem is quadrangular, thickened at and above the nodes and internodes measuring 2-7 cm long. The flowers are in terminal or axillary spikes and are irregular, bisexual, sessile, white with pink or purple spots inside, red in the throat and lip. 1 The leaf of J. gendarussa Burm. F.

*Author for correspondence 
is sometimes applied to treat muscle pains, broken/ fractured bone and boils. 2

J. gendarussa is used in a certain province in the Philippines to ease the pain of women after childbirth. Folks believe that it prevents the "bughat" or the susceptibility of the mother to illnesses and diseases. Also, J. gendarussa is used as a remedy to pains in muscles and fractured bone. 3 Hence, it is important to study the phytochemicals present in the leaf extracts of J. gendarussa Burm. F. to endorse it as a plant that can be used to treat health problems.

\section{Objectives of the Study}

This study was conducted to detect the phytochemicals present in the leaf extract of J. gendarussa Burm. F; to determine the physical properties of J. gendarussa Burm. F. leaf extract in terms of boiling point, colour, density, odour, $\mathrm{pH}$, and miscibility; as well as to determine the percent yield of the leaf. Secondary metabolites present in J. gendarussa Burm. F. leaf extracts, including alkaloid, anthraquinone, leucoanthocyanin, phenolic compounds, saponin, steroid, tannins, and terpenoids, were also investigated.

\section{Methodology}

\subsection{Research Design}

An experimental research design was used in this study. Physical testing and percent yield of the plant extract was also done and computed. Simple mean and average statistical tools were used to assess certain physical properties.

\subsection{Data Gathering Procedures}

\subsubsection{Preparation and Collection of Sample}

Leaves of J. gendarussa were gathered from the province of eastern Samar, Philippines, for which taxonomic identification was done by an expert botanist.

\subsubsection{Preparation of Leaf Extract}

Using a scissor .veswere trimmed from its stem. Only young leaves were used.

The gathered leaves were soaked in $\mathrm{n}$-hexane for $30 \mathrm{~min}$ and then pounded in a mortar and pestle. The extracted juice was then filtered using a Wattman No. 42 filter paper and a funnel, and then the filtrate was collected and put into a clean bottle.

\subsection{Physical Property Analysis of Plant Extract}

\subsubsection{Boiling Point}

About $5 \mathrm{~mL}$ of leaf extract of J. gendarussa was put in a test tube. The tube was then submerged in a water bath and the temperature where the extract started to boil was recorded. The process was repeated thrice.

\subsubsection{Colour}

Colour of the extract of $J$. gendarussa was determined using the sense of sight of a total of five respondents. About $10 \mathrm{~mL}$ of plant extract was contained into a clear Petri dish. Then, using the sense of sight, the respondents described the colour of the extract. Perception of colour from the respondents was gathered and analysed.

\subsubsection{Density}

To test for density, $10 \mathrm{~mL}$ of plant extract was weighed on an analytical balance in a pre-weighed graduated cylinder. The weight of the extract was then recorded and divided by the amount of extract used (in $\mathrm{mL}$ ). The procedure was repeated thrice. Average density was also computed using the equation

\subsubsection{Odour}

Odour of the extract was tested using the olfactory sense of a total of five respondents. About $5 \mathrm{~mL}$ of the extract was contained into a clear transparent beaker. Then, the respondents described the odour of the extract contained in the transparent beaker. Perception of odour from the respondents was gathered and analysed.

\subsection{5. $p H$}

$\mathrm{pH}$ of the leaf extract was determined using a $\mathrm{pH}$ paper. About $5 \mathrm{~mL}$ of the extract was contained in a $50 \mathrm{~mL}$ beaker. Then, a $\mathrm{pH}$ paper was dipped into the extract. After $1 \mathrm{~min}$, colour reaction of the $\mathrm{pH}$ paper was compared with the $\mathrm{pH}$ indicator, and then the $\mathrm{pH}$ was recorded. The procedure was repeated thrice. Average $\mathrm{pH}$ was also computed.

\subsubsection{Miscibility}

To test the miscibility of the plant extract, three solvents were used, namely benzene, water and ethanol. About 2 $\mathrm{mL}$ of the extract was put into nine clear test tubes. Then, 
$10 \mathrm{~mL}$ benzene was poured into three test tubes; another three test tubes were poured with $10 \mathrm{~mL}$ of water, and the remaining three test tubes with $10 \mathrm{~mL}$ ethanol. The nine test tubes were observed for $1 \mathrm{~h}$ to determine the miscibility of extract. The researchers recorded the finding as (1) miscible, (2) slightly miscible or (3) not miscible.

\subsection{Percent Yield}

Percent yield was computed using the formula

\subsection{Screening Test for Active Components}

Screening tests were performed for the confirmation of components including alkaloids, saponins, terpenoids, phenolic compounds, leucoanthocyanin, steroids, tannins and anthraquinones. These substances were detected using the following procedures:

\subsubsection{Alkaloid}

The extract of J. gendarussa was dissolved individually in diluted (2 M) hydrochloric acid and filtered, and then it was subjected to the following tests:

Mayer's test: The filtrates were treated with Mayer's reagent; the formation of a yellow coloured precipitate indicated the presence of alkaloids.

Dragendroff's test: The filtrates were treated with Dragendroff's reagent; the formation of red precipitate indicated the presence of alkaloids.

\subsubsection{Anthraquinone}

The Borntrager's test was used to determine the presence of anthraquinone. Red coloration in the lower ammoniacal layer indicated the presence of anthraquinone.

An equivalent of $10 \mathrm{~g}$ of extracted liquid from the stock plant extract was taken; it was evaporated to incipient dryness over a steam bath. Then to the residue $10 \mathrm{~mL}$ of distilled water was added and filtered. The aqueous filtrate was then extracted twice with a $5 \mathrm{~mL}$ portion of benzene, and combined with the benzene extract. Then the combined benzene extract was divided into two portions. One portion served as the control and other portion was treated with $5 \mathrm{~mL}$ ammonia solution and shaken. Then it was compared to the control tube.

\subsubsection{Saponin}

The capillary test was used to determine the presence of saponin. That is, if the level of the plant extract in the capillary tube is half than in the other tube containing water, the presence of saponin can be inferred.

This was done by loading a capillary tube with the leaf extract by immersing the tube to a height of $10 \mathrm{~mm}$. in the plant extract. Likewise, another capillary tube was loaded with distilled water. Then the two tubes were kept in a vertical position to allow the liquid inside to flow out freely. After sometime, the heights of the liquids in the two tubes were compared.

\subsubsection{Phenolic Compounds}

The detection of phenols was carried out using the ferric chloride test. Leaf extracts were treated with 3-4 drops of ferric chloride solution. The formation of bluish black colour indicated the presence of phenols.

\subsubsection{Tannins}

The gelatin test was used to determine the presence of tannin in the leaf extract. To the leaf extract, $1 \%$ gelatin solution containing sodium chloride was added. The formation of white precipitate indicated the presence of tannins.

\subsubsection{Steroid}

The Libermann-Burchard test was used to detect the presence of terpenoid. A range of colours from blue to green, pink, violet or purple indicated the presence of terpenoid.

An equivalent amount of $10 \mathrm{~g}$ of extract from the prepared plant extract was evaporated to incipient dryness over a steam bath. It was then cooled to room temperature. Then the material was defatted by taking up residue with $12 \mathrm{~mL}$ hexane and $6 \mathrm{~mL}$ water. It was partitioned by gently shaking the mixture in a test tube. The upper hexane layer was pipetted out. Then, the treatment with hexane was repeated until most of the coloured pigments were removed. Hexane was discarded properly. The aqueous layer was then treated with $10 \mathrm{~mL}$ chloroform and the mixture was gently shaken. It was allowed to stand for a few minutes and the chloroform extract was again pipetted off. Then the chloroform extract was dried by filtering through about $100 \mathrm{mg}$ of anhydrous sodium sulfate held over the dry Whattman 42 filter paper. The filtrate was then divided into two portions. One portion served as the control. Then the other portion was treated with three drops of acetic anhydride and then a drop of concentrated sulfuric acid. Any immediate colour change was observed. Then it was set aside for an hour 
and observed for further colour changes. It was then compared with the control and the results were recorded.

\subsubsection{Terpenoid}

An equivalent amount of $10 \mathrm{~g}$ of extract from the prepared plant extract was evaporated to incipient dryness over a steam bath. It was then cooled to room temperature. Then the material was defatted by taking up residue with $12 \mathrm{~mL}$ hexane and $6 \mathrm{~mL}$ water. It was partitioned by gently shaking the mixture in a test tube. The upper hexane layer was pipetted out. Then, treatment with hexane was repeated until most of the coloured pigments were removed. Hexane was discarded properly. The aqueous layer was then treated with $10 \mathrm{~mL}$ chloroform and the mixture was gently shaken. It was allowed to stand for a few minutes and the chloroform extract was pipetted off. Then the chloroform extract was dried by filtering through about $100 \mathrm{mg}$ of anhydrous sodium sulfate held over the dry filter paper. The filtrate was then divided into two portions. One portion served as the control. Then the other portion was treated with three drops of acetic anhydride and then a drop of concentrated sulfuric acid. Formations of blue-green rings indicated the presence of terpenoid in the extract.

\section{Results}

Results were recorded and summarised herein.

\subsection{Physical Properties}

Physical properties of the extract are reported in Table 1.

\subsection{Percent Yield}

By weighing the extracts of J. gendarussa and dividing it by its weight of leaves, percent yield was recorded to be at

Table 1. Physical properties of J. gendarussa extract

\begin{tabular}{|l|l|}
\hline Physical properties & Observation \\
\hline Boiling point & $103.3^{\circ} \mathrm{C}$ \\
\hline Colour & Brown \\
\hline Odour & Pleasant odour \\
\hline Density & $1.02 \mathrm{~g} / \mathrm{mL}$ \\
\hline $\mathrm{pH}$ & 7 (Neutral) \\
\hline \multirow{2}{*}{ Miscibility } & Miscible (in water) \\
\cline { 2 - 2 } & Miscible (in methanol) \\
\cline { 2 - 2 } & Immiscible (in chloroform) \\
\hline
\end{tabular}

Table 2. Phytochemical analysis

\begin{tabular}{|l|l|}
\hline Secondary metabolites tested & Finding \\
\hline Alkaloid & Positive \\
\hline Anthraquinone & Negative \\
\hline Leucoanthocyanin & Negative \\
\hline Phenolic compounds & Negative \\
\hline Saponin & Positive \\
\hline Steroid & Negative \\
\hline Tannin & Negative \\
\hline Terpenoid & Negative \\
\hline
\end{tabular}

$30 \%$. It was documented by collecting about $30 \mathrm{~g}$ of crude J. gendarussa extract from the total $100 \mathrm{~g}$ of leaves used in the conduct of this study.

\subsection{Phytochemical Screening}

Based on the results of this study, only alkaloid and saponin are present in the plant extract of J. gendarussa leaves. Other secondary metabolites such as terpenoids, tannin, anthraquinone, leucoanthocyanin, phenolics, and steroids were found to be absent in the plant extract. These findings are summarised in Table 2.

\section{Discussion}

Justicia gendarussa, commonly known as willow-leaved Justicia, is a small, erect, branched shrub endemic to India. It is useful in the treatment of asthma, rheumatism and colics of children. It may have the potential to be used in male sterilization. Clinical tests are on-going in Indonesia. $\underline{4}$

From the results of this study, J. gendarussa leaf extract was found to be brown in colour and pleasant in odour. Its boiling point is $103.3^{\circ} \mathrm{C}$, with an average density of $1.02 \mathrm{~g} /$ $\mathrm{mL}$, neutral $\mathrm{pH}$ of 7 , and polar in compound constituent as evidenced by its miscibility in water and methanol and immiscibility in chloroform.

Further analysis revealed the presence of alkaloids and saponin only; these secondary metabolites were indicated by an orange and white precipitate for alkaloids and a strong capillary action for saponin comparison to distilled water. Other secondary metabolites were found to be negative in the plant extract, including tannin, phenolic compounds, terpenoids, steroids, anthraquinone and leucoanthocyanin; the absence of coloration and precipitates implied these secondary metabolites are absent in the plant extract. 


\section{Conclusions}

Based on the findings of this study, the following conclusions were drawn:

1. J. gendarussa leaf extract has a high boiling point than water, a neutral $\mathrm{pH}$ of 7 , and is polar in its chemical constituent.

2. J. gendarussa leaf extract has a percent yield of $30 \%$ per $100 \mathrm{~g}$ of leaves.

3. The leaf extract of $J$. gendarussa has the presence of alkaloid and saponin.

4. The leaf extract of J. gendarussa has no tannin, phenolic compounds, terpenoids, steroids, anthraquinone and leucoanthocyanin metabolites.

\section{Recommendations}

The following recommendations are drawn by the researcher in the direction of future work:
1. To characterise and quantify alkaloid and saponin in the extract of J. gendarussa.

2. To determine if there is a difference in secondary metabolite screening.

3. To make use of J. gendarussa as a natural source of alkaloid and saponin.

\section{References}

1. Ratnasooriya W, Deraniyagala S, Dehigaspitiya D. Antinociceptive Activity and Toxicological Study of aqueous leaf extract of Justicia gendarussa Burm. F. in rats. Pharmacogn Mag. 2007;3(11):145-55.

2. Ahmad FB, Holdsworth DK. Medicinal plants of Sabah, East Malaysia-part I. Pharm Biol. 2003;41(5):340-6.

3. Tiwari P, Kumar B, Kaur M, Kaur G, Kaur H. Phytochemical screening and extraction: a review. Int Pharm Sci. 2011;1(1):98-106.

4. Agastian $\mathrm{P}, \mathrm{Williams} \mathrm{L}$, Ignacimuthu $\mathrm{S}$. In vitro propagation of Justicia gendarussa Burm. F. - a medicinal plant. Indian J Biotechnol. 2006;5:246-8. 